REVISTA DE DERECHO UNED, NÚM. 27, 2021

SEGUNDO ACCÉSIT

\title{
DELITOS DE ODIO Y REDES SOCIALES: EL DERECHO FRENTE AL RETO DE LAS NUEVAS TECNOLOGÍAS.
}

\author{
HATE CRIMES AND SOCIAL NETWORKS: \\ THE LAW FACING THE CHALLENGE OF NEW TECHNOLOGIES.
}

\section{JACINTO J. MARABEL MATOS}

Sumario: I. La proliferación de contenidos violentos en Internet: el Ciberodio.- II. Discurso frente a delito: la delimitación jurídica del odio. A. El marco jurídico internacional de una construcción social. B. El artículo 510 CP como paradigma penal frente a la discriminación excluyente. III. El Ciberodio como límite frente a Libertad de Expresión. A. El reconocimiento penal del Ciberodio. B. El juicio de ponderación frente a los límites de la libertad de expresión.- IV. Las alternativas penales: de la especialización en la persecución delictiva a los sistemas de filtrado y la autorregulación de las conductas.- V. Conclusiones.- VI. Bibliografía.

Resumen: Durante la última década hemos asistido al incremento y preeminencia de las redes sociales. Facebook, Twitter, Instagram o Snapchat han cambiado la manera en la que nos relacionamos, multiplicando y viralizando los efectos de nuestras manifestaciones hasta límites insospechados. También de las expresiones que buscan incitar al odio y a la violencia respecto a ciertos colectivos discriminados. En este sentido, todos los registros oficiales apuntan hacia una preocupante proliferación de contenidos violentos delictuales en redes sociales, que se ve facilitada por las dificultades que entraña la aplicación del art. 510.3 del Código Penal frente al derecho de libertad de expresión garantizado en el art. 20.1 de la Constitución Española. Entre las propuestas que abogan por la especialización en la persecución del ciberodio, los sistemas de fil- 
trado o la autorregulación de las conductas, sin duda el Derecho está llamado a protagonizar un papel fundamental ante uno de los principales retos de la Era de las Nuevas Tecnologías.

Palabras clave: Redes sociales, delitos de odio, Derechos Fundamentales, Derecho Penal, nuevas tecnologías.

Abstract: Over the last decade we have witnessed the increase and pre-eminence of the social networks. Facebook, Twitter, Instagram o Snapchat have changed the way we relate, multiplying and viralizing the effects of our manifestations to unsuspected limits. Also from expressions that seek to incite hatred and violence against certain discriminated groups. In this sense, all official records point to a worrying proliferation of violent criminal contents on social networks, which is facilitated by the difficulties involved in the application of article 510.3 of the Penal Code in the face of the right to freedom of expression guaranteed in article 20.1 of the Spanish Constitution. Among the proposals that advocate specialization in the pursuit of cyberodio, filtering systems or the self-regulation of behaviors, the Law is certainly called upon to play a leading role in the face of one of the main challenges of the Era of New Technologies.

Keywords: Social networks, hate crimes, Fundamental rights, Criminal law, new technologies.

\section{LA PROLIFERACIÓN DE CONTENIDOS VIOLENTOS EN INTERNET: EL CIBERODIO.}

La evolución, proliferación y acceso a las nuevas tecnologías de la información y la comunicación (TICs), ha desplazado hacia las redes sociales buena parte de las relaciones que tradicionalmente se sostenían en el ámbito real, en la misma medida que ha incrementado las estadísticas sobre actividades ilícitas que se planifican y ejecutan en Internet.

Sin duda, una de las principales razones de este elevado índice de criminalidad estriba en los movimientos globalizadores, que han revolucionado el campo de la comunicación digital. Las TICs han diluido de tal manera las fronteras físicas, que cualquier usuario puede llegar a ser víctima de ataques indiscriminados en sus bienes y derechos, dirigidos y ejecutados de manera anónima, así como con un alto grado de impunidad, desde los más remotos rincones del 
mundo $^{1}$. Y en este sentido, pese a que en las dos últimas décadas la comunidad internacional ha realizado notables esfuerzos para articular una política penal uniforme y coordinada, dotándose de instrumentos normativos con los que hacer frente al creciente fenómeno de la criminalidad en $\operatorname{Red}^{2}$, esta es una práctica cada vez más común y generalizada, de tal forma que se ha llegado a acuñar un término propio para referirse a ella: el cibercrimen; también conocido como ciberdelincuencia ${ }^{3}$.

Precisamente, la Directiva 2013/40/UE del Parlamento y del Consejo, de 12 de agosto de 2013, relativa a los ataques contra los sistemas de información y por la que se sustituye la Decisión Marco 2005/222/JAI del Consejo, venía a alertar sobre la amenaza creciente que representa la ciberdelincuencia en el espacio de libertad y justicia que garantizan los tratados europeos, haciendo un llamamiento a la coordinación y cooperación entre Estados que a día de hoy está lejos de ser alcanzada ${ }^{4}$. No obstante, debe insistirse en ello, ya que cualquier pretensión de paliar los efectos del cibercrimen pasan por cohesionar un ordenamiento de carácter supranacional ${ }^{5}$. Y es que, como recoge la Memoria de la Fiscalía General del Estado correspondiente al año 2019, Internet se ha convertido en el instrumento predilecto de la actuación delictiva, de tal modo que, en los cuatros

1 En este sentido, uno de los principales problemas estriba en los distintos estándares que sostienen los Estados para definir aquello que debe ser considerado penalmente relevante. Un desarrollo de la cuestión en TERUEL LOZANO, Germán M., «Libertad de expresión en Internet, control de contenidos de las páginas web y sus garantías constitucionales», Revista Aranzadi de Derecho y Nuevas Tecnologías, núm. 25, 2011.

2 Quizás por ser pionero en este ámbito, cabe destacar el Convenio sobre la Ciberdelincuencia, aprobado por el Consejo de Europa en 2001 y vigente en nuestro país desde el 1 de octubre de 2010, en el que se venían a establecer medidas de cooperación en el ámbito de la investigación penal frente a actividades delictivas tales como los fraudes informáticos o la pornografía infantil. Instrumento de Ratificación del Convenio sobre la Ciberdelincuencia, hecho en Budapest el 23 de noviembre de 2001. Boletín Oficial del Estado (BOE), de 17 de septiembre de 2010.

3 Aunque ambos términos pueden ser utilizados de manera indistinta, cierto es que hasta el momento ninguno de ellos ha sido aceptado por la Real Academia Española, que por el contrario admite el anglicismo hacker para referirse a pirata informático, así como los neologismos ciberespacio o cibernauta para aludir a los usuarios de páginas web. Con todo, tanto cibercrimen como ciberdelincuencia constan como acepción de delitos informáticos en el portal institucional de su Diccionario en Red. https://dej.rae.es/lema/ciberdelito [Consultado el 11 de septiembre de 2019].

4 Diario Oficial de la Unión Europea (DOUE), de 14 de agosto de 2013.

5 En este sentido, resulta de sumo interés la Orden PCI/161/2019, de 21 de febrero, del Ministerio de Presidencia, Relaciones con las Cortes e Igualdad, por la que se aprueba la Estrategia Nacional contra el Crimen Organizado y la Delincuencia Grave. BOE, de 22 de febrero de 2019. 
últimos años, las investigaciones por ciberdelitos se han incrementado un 84\% en España, mientras que sólo en 2018 llegaron a incoarse un total de 9.069 procedimientos judiciales al respecto, lo que términos globales equivale a un aumento del 35,84\% frente al mismo tipo de ilícitos cometidos el año anterior ${ }^{6}$.

A la preocupación por el incremento de las cifras de criminalidad informática, se suma la alarma social generada en relación con los delitos de odio instrumentalizados a través de Internet, una modalidad en auge sobre la que, según datos aportados en la misma Memoria, las secciones especializadas incoaron un $18 \%$ más de procedimientos que en el ejercicio anterior. Precisamente, el protagonismo de los delitos de odio se encuentra directamente relacionado con el desarrollo de las redes sociales y las plataformas de comunicación en línea, una cuestión que ha venido a poner el énfasis en la problemática generada en torno al uso inadecuado de estos medios como fuentes de inmediatez y propagación viral para toda clase de contenidos discriminatorios ${ }^{7}$.

En efecto, las redes sociales se han convertido en el instrumento preferido para el desarrollo del ciberodio, entendido como todas aquellas expresiones de odio transmitidas a través de las TICs que, asimiladas al discurso del odio, vendrían amparadas en su mayor parte por el derecho fundamental a la libertad de expresión garantizado en el art. 20.1 de la Constitución Española (CE), resultando reprochables en su caso desde un prisma ético o social, pero indiferentes y por lo tanto no perseguibles desde el punto de vista jurídico $^{8}$. Como luego veremos, en esta definición un tanto apresurada estriba una de las principales dificultades con las que se encuentran los tribunales a la hora de determinar la naturaleza del injusto en

6 SEgARRA CRESPO, María José, Memoria elevada al Gobierno de S.M. presentada al inicio del año judicial por la Fiscal General del Estado, Imprenta Nacional de la Agencia Estatal del Boletín Oficial del Estado, Madrid, págs. 957-959.

7 ELÓSEGUI ITXASO, María. «Las Recomendaciones de la ECRI sobre Discurso del Odio y la adecuación del ordenamiento jurídico español a las mismas», Revista General de Derecho Canónico y Eclesiástico del Estado, núm. 44, 2017, pág. 5.

8 A nuestro entender, el término ciberodio deberá reservarse por tanto para aquellas expresiones que, generadas y difundidas a través de Internet, resultan tipificadas conforme al ordenamiento penal, de tal forma que constituyen una subcategoría específica dentro de la configuración general de los delitos de odio, razonamiento que comparte así mismo gran parte de la doctrina, como refiere, por todos, MORETÓN TOQUERO, M ${ }^{\mathrm{a}}$ Aránzazu. "El Ciberodio, la nueva cara del mensaje del odio: entre la cibercrimanlidad y la libertad de expresión», Revista Jurídica de Castilla y León, núm. 27, 2012; págs. 1-18. 
este tipo de delitos ${ }^{9}$, lo que ha llevado a la Fundación Abogacía Española, junto a otros entes y organismos de carácter público y privado, a identificar al ciberodio como uno de los grandes retos a los que se enfrenta el Derecho en la actualidad ${ }^{10}$.

La delimitación de la responsabilidad del medio difusor o la del sujeto material que actúa de modo virtual, es otra de las dificultades con las que se encuentran los tribunales que a diario enjuician este tipo de delitos, en los que se busca la impunidad a través del anonimato que proporcionan las redes sociales, sirviéndose de perfiles falsos y obstruyendo la identificación de las interfaces necesarias para la investigación de los mismos ${ }^{11}$. La delimitación de responsabilidades penales en el campo de las TICs resulta siempre compleja, ya que en última instancia, gran parte de las medidas normativas implementadas por los Estados para limitar la difusión de contenidos ilícitos en Internet requieren el compromiso efectivo de las grandes multinacionales del sector para mostrarse efectivas. Las decisiones de los prestadores de servicios, titulares de los servidores que dan cabida a presuntos ciberdelitos, revisten un alto grado de responsabilidad empresarial, y en muchos casos estos no operan con la diligencia debida ante el potencial riesgo de lesión de los bienes jurídicos en juego, pese a que su colaboración resulta esencial no solo para la investigación del delito, autorizando los permisos necesarios para rastrear los servidores e identificar a sus presuntos autores virtuales, sino para coadyuvar a retirar en su caso los contenidos o bloquear el acceso a los mismos.

Esta fue una de las principales razones que llevó a la Unión Europea a aprobar un Código de Conducta para la lucha contra la incitación ilegal al odio en Internet, en el que se recogían una serie de medidas para combatir los contenidos ilícitos en línea ${ }^{12}$, que fue sus-

9 Circunstancia que sin duda redunda en la persecución del delito y que, por otro lado, no es nueva, como observaba hace una década la Organización para la Seguridad y la Cooperación en Europa (OSCE) en su guía Preventing and responding to hate crimes. REUTER, Nona (Coord.), Preventing and responding to hate crimes, OSCE, Varsovia, 2009, pág. 9.

10 ASSIEGO CRUZ, Violeta y otros, Delitos de Odio. Guía Práctica de la Abogacía, Fundación Abogacía Española, Madrid, 2018.

11 LÓPEZ SÁNCHEZ, Javier, "Insultos online, ¿soluciones offline?», Actualidad Jurídica Aranzadi, núm. 91, 2015, pág. 9.

12 Recomendación 2018/334/UE de la Comisión, de 1 de marzo de 2018, sobre medidas para combatir eficazmente los contenidos ilícitos en línea. DOUE, de 6 marzo de 2018. Los últimos datos publicados sobre el seguimiento del mismo apuntan grandes avances en la lucha contra la erradicación del cibercrimen, observándose que los sistemas de detección de actividades ilícitas de estas multinacionales consiguieron evaluar el $89 \%$ de los contenidos sospechosos y retirar en el plazo de 
crito el 31 de mayo de 2016 por Facebook, Microsoft, Twitter y YouTube, y al que se incorporó dos años más tarde Google+, Instagram, Snapchat y Dailymotion, subrayando de este modo el compromiso de las grandes empresas del sector en la resolución eficaz del problema a nivel europeo. Sin embargo, la práctica ha venido a demostrar que estas medidas no resultan suficientes, como prueba la reciente Circular emitida por la Fiscalía General del Estado en la que expresamente se advierte sobre el incremento del ciberodio, fomentado por el uso indiscriminado de las TICs ${ }^{13}$. Y es esta una cuestión sobre la que también ha puesto el acento la jurisprudencia, como razonaba por todas la Sentencia del Tribunal Supremo (STS), Sala de lo Penal, Sección 1 a $4 / 2017$, de 18 de enero, concluyendo que la difusión de contenidos digitales «intensifica de forma exponencial el daño de afirmaciones o mensajes que, en otro momento, podrían haber limitado sus perniciosos efectos a un reducido y seleccionado grupo de destinatarios» ${ }^{14}$.

Los guarismos que muestran la proliferación de denuncias en los últimos años avalan dichas tesis, pese a que según la Agencia de Derechos Fundamentales de la Unión Europea, hasta hace bien poco, el $90 \%$ de los casos contabilizados en Europa no llegaba a denunciarse $^{15}$. Quizás porque el ciberodio ha ido acaparando la atención de los medios informativos, en la actualidad la tendencia es más bien la contraria, como revelan los datos ofrecidos por el Sistema Estadístico de Criminalidad del Ministerio del Interior, donde se observa que el fenómeno se ha quintuplicado de manera exponencial en el último lustro ${ }^{16}$.

24 horas aquellos que consideraban delictivos. Ver en este sentido el comunicado de prensa de la Comisión Europea, de 4 de febrero de 2019, Lucha contra la incitación ilegal al odio en línea: el Código de Conducta de la UE garantiza una rápida respuesta, https://ec.europa.eu/commission/presscorner/detail/es/IP_19_805 [Consultada el 10 de octubre de 2019].

13 Circular 7/2019, de 14 de mayo, de la Fiscalía General del Estado, sobre pautas para interpretar los delitos de odio tipificados en el art. 510 del Código Penal. BOE, de 24 de mayo de 2019.

14 STS, Sala de lo Penal, Sección 1 ${ }^{\text {a }}$, 4/2017, de 18 de enero.

15 LÓPEZ ORTEGA, Anna I., "Análisis y evolución de los delitos de odio en España (2011-2015)», Almenara. Revista Extremeña de Ciencias Sociales, núm. 9, 2015, págs. $80-81$.

${ }_{16}$ Entre la ya de por sí alarmante preocupación que se desprende de estos datos, llama la atención que por primera vez la discriminación por motivos ideológicos alcance en 2018 el 33\% sobre el conjunto de los delitos, superando a la tradicional discriminación por motivos racistas o xenófobos que ocupaba el primer lugar en el período estadístico. Los informes anuales del Ministerio del Interior sobre la evolución de los delitos de odio en España pueden consultarse en el portal oficial: http:// www.interior.gob.es/web/servicios-al-ciudadano/delitos-de-odio/estadisticas. [Consultado el 9 de septiembre de 2019]. 
Por su parte, el Informe del Ministerio del Interior sobre la evolución de los delitos de odio en España en 2018 concluía que Internet, con un $68,10 \%$ de los casos registrados, es con diferencia el medio mayoritariamente empleado para la comisión de este tipo delictual, muy por encima de la mensajería vía telefónica $(13,3 \%)$ u otros medios tradicionales de comunicación social $(4,8 \%)^{17}$. El ciberodio se difunde por medio de foros, blogs y páginas específicas alojadas en la web, aunque también a través de juegos online, así como montajes de videos musicales con actitudes subrepticias y letras discriminatorias, pese a que no obstante y según el mismo Informe, se ejecuta en su mayor parte a través de post y tuits redactados en redes sociales, de tal modo que la difusión de expresiones violentas y discriminatorias a través de las mismas representa el 26\% del total de los hechos delictivos comisionados en Internet.

Todos los registros muestran que las redes sociales se han convertido en el instrumento ideal para viralizar los contenidos discriminatorios que caracterizan los delitos de odio. Aunque ciertamente la preocupación por el progresivo incremento de esta tipología delictiva no es nueva, como se desprende de los numerosos textos normativos de carácter internacional suscritos por España, así como de la tipificación, no exenta de controversia tal y como enseguida veremos, de las conductas recogidas en el vigente art. 510 del Código Penal (CP). Un precepto convertido en salvaguarda esencial frente al incontinente fenómeno de la discriminación excluyente, mientras su apartado tercero se ha erigido en paradigma en la lucha contra el ciberodio, en tanto configuración específica del anterior con injusto de mayor relevancia, un agravamiento de las penas previstas en su mitad superior cuando la comisión del delito se lleve a cabo a través de las TICs.

Pese al reconocimiento expreso de la figura del ciberodio en el art. 510.3 CP, la consideración de «ultima ratio» del Derecho Penal ha dado pábulo a ciertas corrientes que han puesto el acento en la especialización de los operadores jurídicos encargados de su persecución, la autorregulación de los prestadores de servicios, la introducción de sistemas de filtrado o el fomento de una educación cívica basada en valores responsables, en tanto fórmulas válidas y supeditadas a la necesidad de coordinar y aunar esfuerzos a partir de un marco jurídico internacional homogéneo, a la hora de tratar de resolver gran parte de los numerosos problemas que generan la deter-

17 CERECEDA FERNÁNDEZ-ORDUÑA, Jaime y otros, Informe sobre la evolución de los delitos de odio en España, Ministerio del Interior, Madrid, 2018, pág. 9.

(C) UNED. Revista de Derecho UNED, núm. 27, 2021 
minación de este tipo de delitos ${ }^{18}$, sin duda uno de los principales retos a los que se enfrenta el Derecho en nuestros días.

\section{DISCURSO FRENTE A DELITO: LA DELIMITACIÓN JURÍDICA DEL ODIO.}

\section{A. El marco jurídico internacional de una construcción social.}

Odiar, detestar, sentir antipatía, incluso rechazo o repugnancia, frente a algo o alguien cuyo mal se desea, no deja de ser un sentimiento íntimo, difícil de cuantificar y determinar. El sentimiento de odio, como tal, carece de relevancia penal. Exteriorizarlo, hacerlo público o difundirlo, e incluso incitar a otros a compartir esa noción de repulsa, que es lo que en sentido genérico se entiende por discurso del odio, en principio tampoco resulta penalmente reprochable, puesto que la manifestación de tales ideas o sentimientos hostiles quedaría protegida por el derecho de libertad de expresión.

Por tanto y en primer lugar debemos dejar claro que una cosa es el discurso del odio y otra su apariencia delictiva. Esta última comienza a tomar forma cuando entran en juego las expresiones intolerantes, entendidas como falta de respeto a las ideas, creencias o prácticas de los demás, fundadas en estereotipos o prejuicios, construidos socialmente y validados respecto a un determinado contexto o territorio, que resultan cambiantes e inciertos a su vez.

En base a dicha volatilidad social, las expresiones intolerantes carecen por sí mismas de punibilidad, constituyendo únicamente manifestaciones concretas del discurso del odio cuando se encuentran basadas en prejuicios discriminatorios graves, de conformidad con las normas penales de cada Estado. Porque, aunque todo acto discriminatorio entraña un trato desigual respecto a una persona o colectividad en razón de etnia, género, edad, ideología o creencias, resulta complicado alcanzar un consenso a nivel internacional sobre qué grado de difusión, incitación o justificación de las expresiones intolerantes podría quedar encuadrado dentro del tipo delictivo común. Por la misma razón, tampoco existe una opinión generalizada sobre el número y características de los colectivos que deberían resultar protegidos frente a la comisión delictiva.

18 TERUEL LOZANO, Germán M. «Expresiones intolerantes, delitos de odio y libertad de expresión: un difícil equilibrio», Revista Jurídica de la Universidad Autónoma de Madrid, núm. 36, 2017, pág. 195. 
Con todo, cabe mencionar fundamentalmente dos instrumentos internacionales que coadyuvan a delimitar de modo uniforme su contornos. Por un lado, la Recomendación $\mathrm{n}^{\circ}$ 20, sobre el Discurso del Odio, adoptada por la Comisión Europea contra el Racismo y la Intolerancia (ECRI) del Consejo de Europa ${ }^{19}$, el 30 de octubre de 1997, en la que este vendría definido como:

«Toda forma de expresión que difunda, incite, promueva o justifique el odio racial, la xenofobia, el anti-semitismo u otras expresiones de odio basadas en la intolerancia, incluida: la intolerancia expresada por el nacionalismo violento y el etnocentrismo, la discriminación y la hostilidad hacia las minorías, migrantes y personas de origen inmigrante ${ }^{20}$.

Por otro, la Decisión del Consejo de Ministros de la Organización para la Seguridad y la Cooperación en Europa n ${ }^{\circ}$ 4/2003, de 2 de diciembre, de la que se extrae que, de entre todas aquellas conductas que podían ser englobadas dentro del discurso del odio, tan sólo cabría calificar como delitos:

«(A) Cualquier infracción penal, incluyendo infracciones contra las personas o las propiedades, donde la víctima, el local o el objetivo de la infracción se elija por su, real o percibida, conexión, simpatía, filiación, apoyo o pertenencia a un grupo como los definidos en la parte B.

(B) Un grupo debe estar basado en una característica común de sus miembros, como su raza real o perceptiva, el origen nacional o étnico, el lenguaje, el color, la religión, el sexo, la edad, la discapacidad intelectual o física, la orientación sexual u otro factor similar» ${ }^{21}$.

19 La ECRI es una institución dependiente del Consejo de Europa, creada tras la primera Cumbre de Jefes de Estado y de Gobierno celebrada en Viena en el mes de octubre de 1993, cuya finalidad es reforzar la coexistencia democrática combatiendo toda forma de intolerancia y discriminación. Operativa desde 1994, las resoluciones de la ECRI deben ser tenidas en cuenta por los 47 Estados que forman parte del Consejo de Europa y pueden consultarse en el portal institucional: www.coe.int

${ }_{20}$ Traducción propia de Recommendation $\mathrm{N}^{\circ} \mathrm{R}$ (97) 20 of the Committee of Ministers to Members States of Hate Speech, adopted by the Committee of Ministers on 30 October 1997 at the 607th meeting of the Ministers' Deputies. https:// search.coe.int/cm/Pages/result_details.aspx?ObjectID $=0900001680505$ d5b [Consultado el 12 de septiembre de 2019].

${ }^{21}$ Conforme con la traducción contenida en el portal oficial del Ministerio del Interior. Http://www.interior.gob.es/web/servicios-al-ciudadano/delitos-de-odio/quees-un-delito-de-odio. [Consultado el 12 de septiembre de 2019]. 
La confrontación de ambos permite extraer una aproximación del concepto jurídico del odio, entendido como todas aquellas expresiones o actividades intolerantes fundamentadas en un prejuicio del sujeto pasivo hacia la víctima, escogida por pertenecer a un colectivo que el autor desprecia u odia, expresamente tipificadas en la legislación nacional. Una interpretación ajustada para un tipo delictual que no ha estado exenta de controversia desde la primigenia regulación operada en la Ley Orgánica (LO) 4/1995, de 11 de mayo, que modificó el CP de $1973^{22}$, como prueba la reciente Circular 7/2019 de la Fiscalía General del Estado, en la que se establecen una serie de notas caracterizadoras para facilitar su persecución y erradicación por parte de las fiscalías especializadas ${ }^{23}$.

Pero para llegar hasta el punto en el que nos encontramos, el Derecho Penal Internacional fue configurando poco a poco la naturaleza jurídica de los delitos de odio, incorporándolos a diversos instrumentos normativos, a partir de la verificación de la propia experiencia y el contexto social de cada Estado. De tal modo que, aunque sigue sin existir un consenso generalizado respeto a los elementos que integran el tipo, cabe admitir sin embargo cierto grado de aquiescencia en cuanto al origen de la noción jurídica del odio, como respuesta colectiva otorgada a las ideologías políticas excluyentes difundidas en el primer tercio siglo pasado, fascismo, nazismo y comunismo fundamentalmente, una vez finalizada la II Guerra Mundial.

En este sentido, es de destacar el trabajo realizado en aquellos años por la recién creada Organización de las Naciones Unidas. La pionera Resolución 96 A (I), emitida por su Asamblea General el 11 de diciembre de 1946, posibilitó la aprobación del primer Convenio para la Prevención y la Sanción del Delito de Genocidio dentro del ámbito internacional, completándose posteriormente con un conjunto de medidas normativas entre las que destacarían las Resoluciones 2106 A (XX) y 2200 A (XXI), dictadas el 21 de diciembre de 1965 y el 16 de diciembre de 1966, respectivamente, que dieron lugar al Convenio Internacional sobre Eliminación de todas las Formas de Discriminación Racial y al Pacto Internacional de Derechos Civiles y Políticos. El art. 22.2 de este último texto rechazaba toda forma de apología de la discriminación, el odio o la violencia, en base a la consagración de la igualdad de derechos y la dignidad de

22 Ley Orgánica 4/1995, de 11 de mayo, de modificación del Código Penal, mediante la que se tipifica la apología de los delitos de genocidio. BOE, de 12 de mayo de 1995,

23 Vid. Circular 7/2019, de 14 de mayo, de la Fiscalía General del Estado. 
las personas, establecidos a su vez en el art. 1 de la Declaración Universal de Derechos Humanos, proclamada en París el 10 de diciembre de 1948, mediante Resolución 217 A (III), así como, fundamentalmente, en el art. 2 de la misma, en el que se proscribía toda clase de discriminación por razón «de raza, color, sexo, idioma, religión, opinión política o de cualquier otra índole, origen nacional o social, posición económica, nacimiento o cualquier otra condición» ${ }^{24}$.

Casi en idénticos términos se expresaba el art. 14 del Convenio para la Protección de los Derechos Humanos y de las Libertades Fundamentales (CDH), aprobado por el Consejo de Europa el 4 de noviembre de 1950, así como el art. 21 de la Carta de los Derechos Fundamentales de la Unión Europea, anexada al vigente Tratado de Lisboa y proclamada conjuntamente, el 7 diciembre de 2000, por el Parlamento, el Consejo y la Comisión ${ }^{25}$. La importancia de ambas prevenciones, sumadas a la anterior normativa internacional, radica fundamentalmente y tal como recoge el art. 10.2 CE, a la hora de interpretar el derecho fundamental de igualdad ante la Ley consagrado en el art. $14 \mathrm{CE}$.

Y sin duda, también contribuye a delimitar esta hermenéutica los esfuerzos realizados desde la ECRI a través de múltiples resoluciones que, no obstante centradas tradicionalmente en el ámbito de la xenofobia y la segregación racial, resultan aplicables con carácter general a toda forma de discriminación e incitación a la violencia en el sentido hasta aquí expuesto. Así, resultan muy relevantes las conclusiones contenidas en la citada Recomendación $\mathrm{n}^{\circ} 20$, de 30 de octubre de 1997, sobre el Discurso del Odio, así como las posteriores Recomendaciones $\mathrm{n}^{\circ} 7$, de 13 diciembre del 2002, sobre Política Ge-

24 Nuestro país acabó ratificando el Convenio para la Prevención y la Sanción del Delito de Genocidio y el Convenio Internacional sobre Eliminación de todas las Formas de Discriminación Racial, adhiriéndose a ambos con reserva a la cláusula de sometimiento a la jurisdicción del Tribunal Internacional de Justicia, el 13 de septiembre de 1968 y el 4 de enero de 1969, respectivamente, mientras que el Instrumento de Ratificación del Pacto Internacional de Derechos Civiles y Políticos sería suscrito una vez entrada en vigor la Ley 1/1977, de 4 de enero, para la Reforma Política. BOE de 8 de febrero de 1969, 17 de mayo de 1969 y 30 de abril de 1977. Respecto a los artículos 1 y 2 de la Declaración Universal de Derechos Humanos, su traducción al español puede consultarse en https://undocs.org/es/A/RES/217(III) [Consultado el 8 de octubre de 2019].

25 Convenio para la protección de los derechos humanos y de las libertades fundamentales, hecho en Roma el 4 de noviembre de 1950; Ley Orgánica 1/2008, de 30 de julio, por la que se autoriza la ratificación por España del Tratado de Lisboa, por el que se modifican el Tratado de la Unión Europea y el Tratado Constitutivo de la Comunidad Europea, firmado en la capital portuguesa el 13 de diciembre de 2007. BOE de 10 de octubre de 1979 y 31 de julio de 2008, respectivamente. 
neral, y $\mathrm{n}^{\circ} 15$, de 8 de diciembre de 2015 , relativa a la Lucha para Eliminar el Discurso del Odio ${ }^{26}$.

Por último, en el seno del Consejo de Europa resulta obligado señalar la Sentencia del Tribunal Europeo de Derechos Humanos (STEDH), Gran Sala, de 8 julio de 1999, Caso Sürek contra Turquía $^{27}$, en la que fue acuñada por vez primera la expresión «discurso del odio» con objeto de enjuiciar la pretensión de amparo de la libertad de expresión consagrada en el art. $10 \mathrm{CDH}$, respecto al editor de una revista en la que se habían vertido expresiones presuntamente injuriosas contra la intervención militar del Estado turco en el Kurdistán. La Sentencia, con la opinión disidente de hasta siete miembros del Tribunal, hizo prevalecer en este caso el derecho a la libertad de expresión del recurrente, si bien acabó concluyendo que el mismo no podía ofrecer una cobertura ilimitada al discurso del odio.

\section{B. El artículo $510 \mathrm{CP}$ como paradigma penal frente a la discriminación excluyente.}

Las Sentencias del Tribunal Europeo de Derechos Humanos pusieron de relieve que la necesaria ponderación de los derechos fundamentales en juego que entrañaba la comisión del tipo de injusto en esta clase de delitos, no conllevaba necesariamente la relevancia penal del discurso del odio. Esto mismo había sido puesto de manifiesto poco antes por nuestro Derecho interno, a raíz de la introduc-

26 Ambas resoluciones pueden ser consultadas en los siguientes enlaces: https://rm.coe.int/ecri-general-policy-recommendation-no-7-revised-on-nationallegislatio/16808b5aaf. https://rm.coe.int/ecri-general-policy-recommendation-n-15-oncombating-hate-speech-adopt/16808b7904 [Consultados el 10 de octubre de 2019].

27 STEDH, Gran Sala, de 8 julio de 1999, Caso Sürek contra Turquía, con opiniones parcialmente disidentes de los jueces Palm, Bonello, Tulkens, Casadevall, Greve, Fischbach y Gölcüklü. Sus fundamentos dieron lugar a toda una serie de pronunciamientos en los que se abordó el problema del discurso del odio frente a la libertad de prensa, expresión y difusión de las ideas por discriminatorias o atentatorias de la dignidad que fueran, entre las que cabe destacar las SSTEDH Sección $3^{\circ}$, de 18 de julio de 2000, Caso Senen contra Turquía; Sección $2^{\circ}$, de 9 de noviembre de 2004, Caso Marasil contra Turquía; Sección 3º de 10 de noviembre de 2004, Caso Dicle contra Turquía; Sección 2a , de 15 de marzo de 205, Caso Gümus y otros contra Turquía; Sección $2^{\mathrm{a}}$, de 13 de septiembre de 2005, Caso Han contra Turquía; Sección $4^{\text {a }}$, de 21 de marzo de 2006, Caso Koc y Tambas contra Turquía; Sección $3^{\text {a }}$, de 9 de noviembre de 2006; Caso Düzgoren contra Turquía; Sección $2^{\circ}$, de 10 de mayo de 2007, Caso Üstün contra Turquía; Sección 2a ${ }^{\text {a }}$, de 31 de junio de 2007, Caso Ulusoy contra Turquía; Sección 3a , de 29 de noviembre de 2007, Caso Demirel y Ates contra Turquía; y Sección 4 ${ }^{\text {a }}$, de 8 de enero de 2008, Caso Yurdatapan contra Turquía. 
ción del art. 165. ter CP con motivo de la aprobación de la citada LO 4/1995, en relación con la redacción del apartado segundo, en el que se definía el delito de apología tras la polémica surgida a raíz de la Sentencia del Tribunal Constitucional (STC) 214/1991, de 11 de noviembre, por la que se otorgó amparo a una antigua víctima de un campo de concentración nazi, después de que su pretensión de protección del derecho al honor, frente al contenido de una publicación en la que se hacía apología del genocidio, no resultase reconocida ante la jurisdicción ordinaria ${ }^{28}$.

Con todo, la vigencia de este pionero art. 165.ter CP fue realmente escasa, apenas un año, ya que la Disposición Derogatoria Única de la LO 10/1995, de 23 de noviembre, del CP, acabó incluyendo el tipo bajo el denominador común de la tolerancia excluyente, en la que, admitiendo como bien jurídico protegido la dignidad de la persona consagrada en el art. 10.1 CE, acabó no obstante diseminando a lo largo y ancho del texto normativo una serie de conductas afines que dificultaban su sistematización e interpretación. Aún hoy, esta disgregación corre el riesgo de convertir los delitos de odio en una suerte de cajón de sastre cuando, como con frecuencia ocurre, se pretende encuadrar en ellos conductas atípicas que en realidad no son sino manifestaciones del legítimo derecho a la libertad de expresión del art. 20.1 CE. De tal modo que nos encontramos con el delito de amenazas a colectivos sociales, étnicos o religiosos, recogido en el art. 170.1 CP; el delito contra la integridad moral del art. $173 \mathrm{CP}$; el delito de torturas por razón de discriminación del art. 174.1 CP; el delito de discriminación en el ámbito labo-

28 La propia Exposición de Motivos de la LO 4/1995, justificaba la inclusión de este tipo de delitos en la legislación española en aras al mandato contenido en la LO 15/1994, de 1 de junio, de Cooperación con el Tribunal Internacional para el Enjuiciamiento de los Presuntos Responsables de Violaciones Graves del Derecho Internacional Humanitario cometidas en el territorio de la ex-Yugoslavia, que comportaba la adopción de una serie de medidas para el cumplimiento de la Resolución 827 (1993), de 25 de mayo, adoptada por el Consejo de Seguridad de las Naciones Unidas para la creación de dicho Tribunal, así como al conjunto de instrumentos internacionales anteriormente citados, con cuya adhesión nuestro país se comprometía a eliminar todas formas de discriminación racial. De este modo, en su redacción original el art. 165 ter. CP venía a establecer que «1. Los que provoquen o inciten, directamente o mediante la apología, a través de medios de comunicación o por cualquier otro sistema que facilite la publicidad, a la discriminación de personas o grupos por motivos referentes a su origen racial, étnico o nacional, o a su ideología, religión o creencias, serán castigados con la pena de prisión menor en grado mínimo o medio y multa de 100.000 a 1.000 .000 de pesetas. 2. La apología existe cuando, ante una concurrencia de personas o por cualquier medio de difusión, se expongan ideas o doctrinas que ensalcen el crimen o enaltezcan a su autor y que, por su naturaleza y circunstancias, puedan constituir una incitación directa a cometer delito». 
ral del art. 314 CP; el delito de provocación a la discriminación, la violencia u odio del art. 510; el delito de denegación discriminatoria de servicios públicos del art. $511 \mathrm{CP}$; de prestaciones profesionales o empresariales del art. $512 \mathrm{CP}$; el delito de asociación ilícita para promover la discriminación del art. 515.4 CP; los delitos contra los sentimientos religiosos de los arts. 522 a 524 CP; el delito de escarnio o vejación del art. $525 \mathrm{CP}$; y los delitos de negación del genocidio y de lesa humanidad de los arts. 607 y 607 bis. CP.

Sin perjuicio de lo anterior, la redacción de estos artículos en la LO 10/1995, aparentemente dejaba al albur de la interpretación de los tribunales la protección del bien jurídico protegido cuando frente a los mismos se anteponía el art. $20.1 \mathrm{CE}^{29}$. Y como no era este un problema único de nuestros tribunales, la jurisprudencia en materia de Derechos Humanos comenzó a fundamentar de manera más clara y precisa la separación entre el «hate speech» o discurso del odio, que en su caso podría quedar amparado por la libertad de expresión, hacia el «hate crime» o delito de odio, cuya relevancia penal sería puesta de manifiesto por vez primera en la STEDH, Sección $1^{\circ}$, de 23 de febrero de 2006, Caso Ognyanova contra Bulgaria, y continuada en las posteriores SSTEDH, Sección $2^{\circ}$, de 14 de diciembre de 2010, Caso Milanovic contra Serbia; Gran Sala, de 3 de julio de 2015, Caso Géorgie contra Rusia; y Sección 5 , de 28 de mayo de 2015, Caso Y contra Eslovenia. Sus razonamientos serían asumidos por la STC 235/2007, de 7 de noviembre, para fundamentar la declaración de inconstitucionalidad del citado art. $607.2 \mathrm{CP}^{30}$, forzando, junto a la obligada transposición de la Decisión Marco 2008/913/JAI, del Consejo de la Unión Europea, de 28 de noviembre de 2008, relativa a la lucha contra determinadas formas y manifestaciones de ra-

29 Tal es así, que en los veinte años que preceden a la reforma de 2015, tan solo se produjeron seis condenas en aplicación del delito de provocación a la discriminación al odio y a la violencia, aunque tan sólo una de ellas fue confirmada en casación por la STS, Sala de lo Penal, Sección 1a, 259/2011, de 12 de abril, si bien poniendo de manifiesto la incoherencia de gravedad de la pena establecida en la incitación indirecta al odio tipificada en el art. $510 \mathrm{CP}$, respecto a la incitación indirecta del genocidio del art. $607.2 \mathrm{CP}$, conforme con la interpretación sostenida por la STC 235/2007, de 7 de noviembre.

30 El texto del entonces vigente artículo 607.2 establecía que « la difusión por cualquier medio de ideas o doctrinas que nieguen o justifiquen los delitos [de genocidio y afines] tipificados en el apartado anterior de este artículo, o pretendan la rehabilitación de regímenes o instituciones que amparen prácticas generadoras de los mismos, se castigará con la pena de prisión de uno a dos años». Ley Orgánica 10/1995, de 23 de noviembre, del Código Penal. BOE, de 24 de noviembre de 1995. 
cismo y xenofobia mediante el Derecho Penal ${ }^{31}$, la reforma operada finalmente mediante LO $1 / 2015$, de 30 de marzo ${ }^{32}$.

En esta ocasión, el legislador optó por distinguir dos grupos de conductas de entre aquellas que podían ser calificadas como delitos de odio en relación con el art. $510 \mathrm{CP}$, teniendo en cuenta si la acción promovía la violencia directa contra grupos minoritarios por cuestiones étnicas, racistas o ideológicas, o si estos tan sólo suponían actos de humillación o menosprecio contra los mismos, sin perjuicio en este último caso de contemplar penalidades agravadas respecto de aquellas acciones que favorecieran un clima de violencia u hostilidad hacia los colectivos minoritarios a las que iban dirigidas ${ }^{33}$.

De este modo y en cuanto al elemento subjetivo, el primer apartado vino a establecer que tanto el odio, como en su caso la hostilidad, la discriminación o la violencia, debían ir dirigidas contra un grupo minoritario, o contra una persona determinada por razón de su pertenencia a aquél, fundado siempre en razones de etnia, ideología, religión, creencias, situación familiar, etnia, nacionalidad, sexo, orientación o identidad sexual, género, enfermedad o discapa$\operatorname{cidad}^{34}$. A nuestro juicio, la relación contenida para este tipo de deli-

31 El principal objetivo de dicha Decisión Marco era el de establecer sanciones penales efectivas y disuasorias frente a las manifestaciones graves de racismo y xenofobia, tipificando la negación del genocidio y fomentando la cooperación judicial en continuidad a la Acción 96/443/JAI del Consejo de la Unión Europea, de 15 de julio de 1996, adoptada sobre la base del art. K.3 del Tratado de la Unión Europea relativa a la acción contra el racismo y la xenofobia. Art. 1 Decisión Marco 2008/913/JAI del Consejo, de 28 de noviembre de 2008, relativa a la protección conjunta de todas las formas y manifestaciones de racismo y xenofobia mediante el Derecho penal. BOE, de 6 de diciembre de 2008.

32 Ley Orgánica 1/2015, de 30 de marzo, por la que se modifica la Ley Orgánica 10/1995, de 23 de noviembre, del Código Penal. BOE nº 77, de 31 de marzo de 2015. En su momento, la doctrina penal fue sido muy crítica sobre la oportunidad de su reforma, como refieren entre otros ALCÁCER GUIRAO, Rafael, " Discurso del odio y discurso político. En defensa de la libertad de los intolerantes», Revista Electrónica de Ciencia Penal y Criminología, núm. 14, 2011, págs. 1-32.GÓMEZ MARTíN, Victor, "Incitación al odio y género. Algunas reflexiones sobre el nuevo art. 510 CP», Revista electrónica de ciencia penal y criminología, núm. 18, 2016, págs. 1-25; TERUEL LOZANO, Germán M., "La libertad de expresión frente a los delitos de negacionismo y de provocación al odio y a la violencia: sombras sin luces en la reforma del Código penal», InDret: Revista para el Análisis del Derecho, núm. 4, 2015, págs. 1-52.

33 ASSIEGO CRUZ, V. Ob.cit., págs. 14-15.

34 Como quiera que la vulnerabilidad intrínseca del colectivo resulta un juicio de valor previo que no requiere acreditación, una parte de la doctrina ha llegado a entender que el término "grupo" incluido en el tipo, admitía una interpretación analógica que abarcaba la aporofobia, la gerontofobia y todos aquellas manifestaciones intolerantes dirigidas contra los colectivos de jueces, fiscales y policías. Entre otros, Goyena Huerta afirma que en la reforma de 2015 el legislador dejó claro 
tos no se encuentre supeditada a interpretación analógica, sino que antes bien resulta una lista cerrada en la que el bien jurídico protegido es la dignidad de los colectivos históricamente desfavorecidos, puesto que el ordenamiento penal admite otra serie de respuestas punitivas respectos aquellos delitos que, como las calumnias o injurias, son atentatorias del derecho del honor o la propia imagen.

El catálogo contemplado en art. 510.1 CP resulta por tanto una relación de circunstancias tasadas y cerradas, ya que en otro caso y en nombre del bien común, como refiere Güerri Ferrández, dicho precepto fomentaría una tendencia hacia la ampliación continua que podría acabar socavando la propia autonomía de los individuos $^{35}$. Por tanto, en base a ello, el principal elemento a tener en cuenta en estos casos es la afectación a la dignidad y libre desarrollo de la personalidad de los colectivos vulnerables que se relacionan, dado que el odio genérico de los delitos tipificados en el art. $510 \mathrm{CP}$, no requieren una incitación, directa o indirecta, a la realización de actos de violencia, frente a las manifestaciones específicas del discurso del odio contemplas en el enaltecimiento del terrorismo y menosprecio a las víctimas del art. $578 \mathrm{CP}$, así como la difusión de mensajes que incitan a la comisión de actos terroristas del art. 579 $\mathrm{CP}$, que sí incorporan la potencialidad de dicho riesgo ${ }^{36}$.

Por otro lado y precisamente por tratarse de una construcción social, los sentimientos de odio no resultan perseguibles en sí mismos. El ilícito penal necesita de una instigación previa a la comisión de los hechos discriminatorios, de forma que exista un riesgo o amenaza real, aunque esta resulte meramente potencial o latente, de que la comisión de los mismos va a ser llevada a cabo. Esto quiere decir que la legítima injerencia en el ámbito de la libertad de expresión que supone la sanción penal de los delitos de odio, deberá estar sólidamente fundada en la constatación fehaciente de una situación de riesgo para los derechos de las personas o para el propio sistema de liberta-

esta circunstancia, incluyendo la referencia al grupo en el artículo $510 \mathrm{CP}$ y omitiéndola del agravante a la discriminación del $22.4^{\mathrm{a}} \mathrm{CP}$, debiendo interpretarse de ello que, entre los sujetos protegidos en los delitos de odio del artículo $510 \mathrm{CP}$, cabe incluir a policías, jueces o fiscales. GOYENA HUERTA, Jaime, "Algunas cuestiones penales sobre el discurso del odio", Revista Aranzadi de Derecho y Proceso Penal, núm.49, 2018.

35 GÜERRI FERNÁNDEZ, Cristina, «La especialización de la fiscalía en materia de delitos de odio y discriminación», InDret, Revista para el Análisis del Derecho, núm. 1, 2015, pág. 24. Por su parte, Teruel Lozano ha criticado la ampliación de los supuestos recogidos en la reforma, que a su juicio adolecen de falta de taxatividad y generan un efecto disuasorio en el legítimo ejercicio de la libertad de expresión. TERUEL LOZANO, G.M. «Expresiones...», Ob. cit., pág. 192.

36 STS, Sala de lo Penal, Sección $1^{\text {a }}$, 646/2018, de 14 de diciembre. 
des que consagra la sociedad democrática. Los tribunales están obligados por tanto a realizar una interpretación ponderada de los derechos constitucionales en juego, con la finalidad de no subvertir los bienes jurídicos relevantes que se encuentran directamente relacionados con el derecho a la dignidad de las personas garantizado en el art. $10 \mathrm{CE}$, con los límites de la libertad de expresión recogida en el art. 20.1 CE, pues en palabras de la STC 112/2016, de 6 de junio, de lo que se trata es de desterrar «todo riesgo de hacer del Derecho Penal un factor de disuasión del ejercicio de la libertad de expresión, lo que, sin duda, resulta indeseable en el Estado democrático» ${ }^{37}$.

En este sentido, una de las principales dificultades estriba en determinar la concurrencia de la intención que guía al sujeto activo en estos casos. La conducta del autor debe estar guiada por un «animo iurandi», una voluntad de denigrar u estigmatizar a una persona o grupo de personas a través de un sentimiento de hostilidad u odio, motivado por las razones anteriormente referidas, como elemento esencial para la admisión del tipo delictivo. No es necesario por tanto promover o fomentar la comisión de un acto concreto, sino que basta la incitación indirecta para que concurra el mismo, si bien habrá de comprobarse que dicha provocación tiene entidad suficiente para poner en peligro los bienes jurídicos protegidos ${ }^{38}$. Porque en definitiva, tal y como está configurado el delito de odio, este presenta un dolo, una intención provocadora para fomentar, promocionar o incitar a la realización de actos que menoscaben bienes jurídicos de terceros, que requiere la acreditación fehaciente de su probanza $^{39}$. Cuestión esta última que no resulta sencilla, en la medida en que habrá de verificarse que esa intención está relacionada, directa o indirectamente, como asegura la jurisprudencia «con alguna de las motivaciones que han determinado la tipificación de la conducta a la luz de los precedentes internos e internacionales,

37 STC 112/2016, de 6 de junio.

38 Para Elósegui, «el discurso debe tener como intención el incitar o esperar razonablemente el efecto de incitar a otros a cometer actos de violencia, intimidación, hostilidad o discriminación contra quienes va dirigido el discurso crítico, ya que de este modo esto constituye una forma especialmente seria de discurso de odio. Es decir, el elemento de incitación implica que exista una clara intención de incitar a cometer actos de esos tipos, o un riesgo inminente de que esos actos ocurran a consecuencia de ese particular discurso de odio utilizado». ELÓSEGUI ITXASO, M.,Ob.cit., pág. 17.

39 La expresión "fomentar, promover o incitar» ha sido duramente criticada por su carácter expansionista, argumentando algunos autores que en estos casos hubiera bastado con el término «incitar». Por todos, ALCÁCER GUIRAO, Rafael, «Libertad de expresión, negación del holocausto y defensa de la democracia. Incongruencias valorativas en la jurisprudencia del TEDH», Revista española de Derecho Constitucional, núm. 97, 2013, págs. 309-341. 
de manera que no es posible sancionar mediante el art. $510 \mathrm{CP}$, sino solo las que encuentren encaje en la prohibición constitucional de discriminación y en el consecuente principio que proclama la igualdad de todas las personas ante la Ley» ${ }^{40}$.

La intención del autor no requiere por tanto de un «animus» singularizado que busque humillar única y exclusivamente a los destinatarios de la acción, sino que al autor le basta con conocer los elementos del tipo y actuar motivado en consecuencia. En la expresión recogida por las SSTS, Sala de lo Penal, Sección $1^{\text {a }}$, 846/2015, de 30 de diciembre y 820/2016, de 2 de noviembre, «al sujeto activo le basta con conocer el carácter objetivamente humillante y vejatorio de las expresiones consideradas aislada y contextualmente, y asumirlo y difundirlo haciéndolo propio, buscando provocar un clima favorable a su reproducción o un germen remoto pero real, de nuevas acciones de esa naturaleza, acciones que cuartean los pilares del Estado de Derecho» ${ }^{41}$.

En cuanto a la verificación de esa voluntariedad, la misma se determina a partir de la constatación de una aptitud o idoneidad en grado tal que sea suficiente por sí sola para generar el clima de odio o discriminación necesario que conlleve ulteriores acciones de intolerancia, frente al colectivo minoritario o frente a sus integrantes. Como recoge la STS, Sala de lo Penal, Sección 1'a , 72/2018, de 9 de febrero, la intención «ha de ser constatada a partir del contenido de las expresiones vertidas; [puesto que] el dolo de estos delitos se rellena con la constatación de la voluntariedad del acto y la constatación de no tratarse de una situación incontrolada o una reacción momentánea, incluso emocional, ante una circunstancia que el sujeto no ha sido capaz de controlar ${ }^{42}$.

En similares términos se expresa también la STS, Sala de lo Penal, Sección $1^{\mathrm{a}}, 646 / 2018$, de 14 de diciembre, para la que: «El elemento que caracteriza a los delitos de odio es el ánimo subjetivo que conduce al autor a la comisión del hecho agresivo, lo que permite excluir un animus ajeno al contenido agresivo. El ánimo consiste en la animadversión hacia la persona, o hacia colectivos que, unificados por el color de su piel, por su origen su etnia, su religión, su discapacidad, su ideología, su orientación o su identidad sexual, o por su condición de víctimas, conforman una aparente unidad que

40 Auto TSJ de Cataluña, Sala Civil y Penal, Sección $1^{\text {a }}, 72 / 2028$, de 28 de junio.

41 STS, Sala de lo Penal, Sección $1^{\text {a }}, 846 / 2015$, de 30 de diciembre, citada a su vez las posteriores SSTS, de misma Sala y Sección, 335/2017, de 11 de mayo y 59/2019, de 5 de febrero.

42 STS, Sala de lo Penal, Sección $1^{\text {a }}$, 72/2018, de 9 de febrero. 
permite configurar una serie de tipos de personas. Por otra parte, desde la tipicidad objetiva, las expresiones y actos han de tener una gravedad suficiente para lesionar la dignidad de los colectivos contra los que se actúa... Lo que es objeto de castigo en los delitos de odio, no puede ser la expresión de una idea, sino cuando se haga de modo que incorporen una provocación al odio, a la discriminación, o a la violencia, infringiendo los valores constitucionales de la dignidad humana y de la no discriminación por causa de nacimiento, origen racial, sexo o religión, o por cualquier otra circunstancia de carácter personal o social a los que se refieren los artículos 10 y 14 de la Constitución. El problema de la tipicidad de estos delitos surge a la hora de dar contenido a la provocación al odio o a la comisión de delitos en concreto» ${ }^{43}$.

$\mathrm{Y}$ es que, en efecto, una vez delimitado el "animo iurandi», surge otra dificultad añadida, como es la de determinar la eventual gravedad de la acción que el sujeto activo se ha representado conscientemente. Dado que no toda discriminación o diferencia de trato puede ser calificada como delito de odio, habrá que valorar entonces si la conducta de autor conlleva una justificación objetiva y razonada de los elementos del tipo. Una conducta «que sólo pueda ser entendida desde el desprecio a la dignidad intrínseca que todo ser humano posee por el mero hecho de serlo», en expresión de la Fiscalía General del Estado ${ }^{44}$, cuya intención debe ser lo suficientemente grave para representarse una contingencia futura para la pacífica convivencia de la sociedad. Un riesgo potencialmente grave dirigido hacia terceros o hacia el propio sistema de libertades que, como luego veremos, deberá acreditar su injerencia con el estándar de derecho de la libertad de expresión, pues tal y como afirma Tajadura Tejada, en estos supuestos el peligro potencialmente representado en la voluntad del sujeto fundamenta la antijuridicidad de

43 STS, Sala de lo Penal, Sección $1^{\circ}, 646 / 2018$, de 14 de diciembre, citada a su vez por las SSTS, de misma Sala y Sección, 47/2019, de 4 de febrero y 185/2019, de 2 de abril.

44 Para la Fiscalía General del Estado, el delito de odio «supone, en definitiva, un ataque al diferente como expresión de una intolerancia incompatible con la convivencia. Precisamente por ello, serán objeto de persecución penal aquellas conductas que supongan una infracción de las normas más elementales de tolerancia y convivencia que afectan a los valores y principios comunes a la ciudadanía, invadiendo la esfera de dignidad propia de cualquier ser humano y que, como tales, deben ser consideradas como un ataque a los elementos estructurales y vertebradores del orden constitucional y, en definitiva, a todo el sistema de derechos y libertades propio de una sociedad democrática». Vid. Circular 7/2019, de 14 de mayo.

(C) UNED. Revista de Derecho UNED, núm. 27, 2021 
la acción, antes que un injustificado adelanto de la barrera punitiva por parte del Estado ${ }^{45}$.

En definitiva, la aplicación del tipo penal exige la acreditación de un vínculo causal necesario entre las expresiones intolerantes y el efecto lesivo, riesgo o peligrosidad del mismo, por lo que su verificación requiere en todo caso un juicio de inferencia riguroso y pormenorizado. Una hermenéutica severa y precisa que, dado que el lenguaje admite diversas interpretaciones, como se afirma en la STS, Sala de lo Penal, Sección 1 ${ }^{\mathrm{a}}$, 72/2018, de 9 de febrero, habrá de prestar atención al análisis de las palabras y al sentido o intención de las expresiones vertidas por el autor: "valorando y atendiendo a las circunstancias concurrentes, así como a la expresión de las ideas vertidas y las circunstancias concurrentes esto es, si la conducta que se enjuicia constituye el ejercicio legítimo del derecho fundamental a la libertad de expresión y, en consecuencia, se justifica por el valor predominante de la libertad o, por el contrario, la expresión es atentatoria a los derechos y a la dignidad de las personas a que se refiere, situación que habrá de examinarse en cada caso concreto» ${ }^{46}$.

Precisamente, para facilitar la determinación de las expresiones constitutivas de delito a las que alude la jurisprudencia, la citada Recomendación ECRI $n^{\circ} 15$, de 8 de diciembre de 2015, fija unas pautas interpretativas en el sentido de verificar:

«A) El contexto en el que se utiliza el discurso de odio en cuestión (especialmente si ya existen tensiones graves relacionadas con este discurso en la sociedad).

B) La capacidad que tiene la persona que emplea el discurso de odio para ejercer influencia sobre los demás (con motivo de ser por ejemplo un líder político, religioso o de una comunidad).

C) La naturaleza y contundencia del lenguaje empleado (si es provocativo y directo, si utiliza información engañosa, difusión de estereotipos negativos y estigmatización, o si es capaz por otros medios de incitar a la comisión de actos de violencia, intimidación, hostilidad o discriminación).

45 TAJADURA TEJADA, Javier, «Libertad de expresión y negación del genocidio: comentario crítico a la STC de 7 de noviembre de 2007", Revista Vasca de Administración Pública, núm. 80, 2008, pág. 242.

46 STS, Sala de lo Penal, Sección 1a , 72/2018, de 9 de febrero. 
D) El contexto de los comentarios específicos (si son un hecho aislado o reiterado, o si se puede considerar que se equilibra con otras expresiones pronunciadas por la misma persona o por otras, especialmente durante el debate).

E) El medio utilizado (si puede o no provocar una respuesta inmediata de la audiencia como en un acto público en directo).

F) Lade mezclarse en actos de violencia, intimidación, hostilidad o discriminación) $»^{47}$.

En definitiva, las circunstancias específicas en las que se generan los delitos de odio, obligan a una valoración del contexto, el tono y el alcance de las manifestaciones, así como principalmente de la difusión del mensaje que incita a la humillación y al desprecio, que en el caso de las redes sociales se encuentra directamente relacionado con la idoneidad del medio, puesto que como concluía la STS, Sala de lo Penal, Sección 1a, 259/2011, de 12 abril, del mismo «dependen tanto del contenido de lo difundido como de la forma en que se hace la difusión, sin que pueda dejar de valorarse la sociedad o el ámbito social al que se dirigen los actos cuestionados» ${ }^{48}$.

\section{EL CIBERODIO COMO LÍMITE A LA LIBERTAD DE EXPRESIÓN.}

\section{A. El reconocimiento penal del Ciberodio.}

Una de las novedades más interesantes de la reforma penal del 2015 fue el reconocimiento del ciberodio, articulado de manera explícita entre los elementos del tipo recogidos en el art. 510.3 CP, como singularidad agravada del delito específico de odio contemplado en los anteriores apartados. Pues en efecto, este apartado venía a referirse expresamente al mismo al establecer que: «Las penas previstas en los apartados anteriores se impondrán en su mitad superior cuando los hechos se hubieran llevado a cabo a través de un medio de comunicación social, por medio de internet o mediante el uso de tecnologías de la información, de modo que, aquel se hiciera accesible a un elevado número de personas» ${ }^{49}$.

47 Vid. ECRI n ${ }^{\circ} 15$, de 8 de diciembre de 2015, relativa a la Lucha para Eliminar el Discurso del Odio.

48 STS, Sala de lo Penal, Sección 1 a , 259/2011, de 12 abril.

49 Vid. art. 510.3 LO $1 / 2015$, de 30 de marzo, por la que se modifica la LO 10/1995, de 23 de noviembre, del CP. 
De este modo, pese a que los apartados a) y c) del art. $510.1 \mathrm{CP}$ determinaban que la conducta fuera realizada públicamente, exigencia que admitía en el apartado b) del art. 510.2 CP la posibilidad de difundirla genéricamente a través de cualquier medio de comunicación, con la nueva regulación ambos debían entenderse de carácter restringido, puesto que la voluntad del legislador fue la de cualificar expresamente la propagación de su comisión en el art. $510.3 \mathrm{CP}$, optando por agravar la pena cuando se acreditase que las expresiones discriminadoras o denigrantes hubieran alcanzado a un indeterminado número de receptores, asimilando su difusión masiva tanto en relación con las TICs como con las redes sociales.

En cuanto a la idoneidad del medio empleado, que el tipo circunscribe expresamente al uso de las TICs, este constituye en apariencia una relación casi inabarcable de formas de difusión en constante transformación. Su misma naturaleza provoca que la persecución del ciberodio por parte de las Fuerzas y Cuerpos de Seguridad del Estado se haya convertido en una tarea ardua y agotadora, rastreando protocolos de direcciones electrónicas o proponiendo a las autoridades judiciales el cierre de servidores, cuando la mera existencia de blogs, foros y chats justifican por sí solas la difusión de expresiones o manifestaciones contrarias a los colectivos minoritarios recogidos en el art. $510 \mathrm{CP}$, que se acentúa aún más en el caso de las redes sociales, por ser este sin duda el medio digital preferido para la consumación de la modalidad delictiva. Tal es así que el citado Informe del Ministerio del Interior sobre la evolución de los delitos de odio en España correspondiente al año 2018, recoge que el $25,9 \%$ de los mismos se lleva a cabo a través de la impunidad que les conceden las redes sociales ${ }^{50}$.

Este alarmante porcentaje sobre el cómputo total de los delitos de odio cometidos en nuestro país, obedece entre otros factores a que los usuarios de redes sociales no son conscientes de la gravedad de los hechos y estiman que la difusión de un simple tuit del que no son autores les exime de responsabilidad penal, cuando lo cierto es que la mera propagación del mensaje al que se refiere el tipo no distingue entre original o sucedáneo, coadyuvando a servir de correa de transmisión masiva la existencia de seguidores dispuestos a reproducir las expresiones discriminatorias una y otra vez ${ }^{51}$. Así, dado que

50 CERECEDA FERNÁNDEZ-ORDUÑA, J. y otros, Ob.cit., pág. 9.

51 Precisamente, en la STS, Sala de lo Penal, Sección 1a , 72/2018, de 9 de febrero, se condenó a un usuario de redes sociales, estimando entre otras cuestiones el peligro potencial de difusión del mensaje en los dos mil seguidores que habitualmente reproducían a su vez el contenido de los mismos, conducta buscada cons- 
el principal elemento del tipo reside en la potencial peligrosidad del mensaje, no es necesario que el mismo deba ser leído, sino que basta que un número eventualmente elevado de usuarios haya podido tener acceso para la consumación del ilícito. De ahí que haya que tener cuidado en dar pábulo a manifestaciones atentatorias de la dignidad de terceros, sin detenerse a pensar en el impacto mediático y los efectos devastadores que puede llegar a alcanzar un retuiteo descontrolado. Porque precisamente esa posibilidad real de difusión indiscriminada, y por lo tanto de acceso masivo al mismo, es la que llevó a la STC 235/2007, de 7 de noviembre, a concluir que «la tipicidad no resulta de la mera difusión, sino de la difusión en condiciones de crear un peligro real para el bien jurídico que se protege ${ }^{52}$.

Consciente de ello, la Fiscalía General del Estado ha puesto el acento en la necesidad de valorar de manera rigurosa el contexto del mensaje que puede llegar a ser reproducido hasta la saciedad en las redes sociales, estableciendo entre las pautas interpretativas para su verificación: «En primer lugar que la propia escritura permite una cierta reflexión sobre lo que se escribe, por lo que no es asumible de forma acrítica la alegación de la reacción espontánea o incontrolable; en segundo lugar, la propia conciencia de la utilización de un medio idóneo para alcanzar una mayor difusión del mensaje; en tercer lugar, la reiteración o no de la conducta, en la misma o en distintas fechas; y, finalmente, que se trate de expresiones objetivamente humillantes, agresivas o hirientes, que no admitan una posible interpretación racional diferente de una mera expresión de odio o discriminación ${ }^{53}$.

En efecto, en tanto la mera expresión de odio o discriminación puede quedar amparada por el núcleo esencial de protección del art. $20.1 \mathrm{CE}$, se hace necesario que el discurso se encuentre fundamentado en expresiones humillantes, agresivas o hirientes contra los colectivos discriminados, para poder admitir la concurrencia de un delito de odio. Y ello, porque, como elocuentemente recuerda la STS,

cientemente por el autor y en cuya esencia gravitaba la fundamentación del art. $510.3 \mathrm{CP}$.

52 Vid. STC 235/2007, de 7 de noviembre. En similares términos se expresó posteriormente la STS, Sala de lo Penal, Sección $1^{\mathrm{a}}$, 846/2015, de 30 de diciembre, subrayando que, dado que el uso generalizado de redes sociales «acelera la difusión de mensajes escritos hasta acercarlos en su dinámica a las manifestaciones verbales, por su rápida génesis y transmisión inmediata, sigue siendo un factor relevante a la hora de evaluar el tipo subjetivo y el contexto que se trate de expresiones escritas, exigir en todo caso cierta mayor reflexión, puesto que se prestan a ser releídas antes de la difusión».

53 Vid. Circular 7/2019, de 14 de mayo, de la Fiscalía General del Estado. 
Sala de lo Penal, Sección $1^{\text {a }}$, 4/2017, de 18 de enero, «entre el odio que incita a la comisión de delitos, el odio que siembra la semilla del enfrentamiento y que erosiona los valores esenciales de la convivencia, y el odio que se identifica con la animadversión o el resentimiento, existen matices que no pueden ser orillados por el juez penal con el argumento de que todo lo que no es acogible en la libertad de expresión resulta intolerable y, por ello, necesariamente delictivo ${ }^{54}$.

Y es que, en definitiva, las normas no están para proteger el buen gusto. Nuestra Constitución ampara las ideologías por muy extremistas o supremacistas que sean, así como la exposición crítica o la difusión de opiniones, aun cuando las mismas sean desabridas y puedan molestar o inquietar a quienes van dirigidas. El ordenamiento constitucional protege incluso a quienes lo niegan, ya que en términos generales el derecho a la libertad de expresión admite la protección de cualquier idea, por rechazable, perniciosa o aberrante que objetivamente pudiera parecer a muchos desde la perspectiva de los valores éticos, pues así lo requieren el pluralismo, la tolerancia y el espíritu de apertura, sin los cuales no existiría la sociedad democrática. Ahora bien, esta misma doctrina constitucional establece que la libertad de expresión no es un derecho absoluto, sino que está sujeta a las restricciones que pongan en manifiesto peligro la convivencia pacífica de los ciudadanos o la protección de otros bienes jurídicos, como la libertad y la dignidad de las personas ${ }^{55}$.

En los delitos de odio, el ataque a los bienes jurídicos protegidos no se detiene por tanto en la mera amenaza que representa el discurso discriminatorio frente a los principios de libertad o igualdad, sino que por su propia naturaleza el mismo está dirigido fundamentalmente a lesionar la dignidad de la persona, denigrándola o discriminándola. Es por esto por lo que el legislador ha optado por incluirlos entre «los delitos cometidos con ocasión del ejercicio de los derechos fundamentales y de las libertades públicas garantizados por la Constitución» ${ }^{56}$, ya que el núcleo esencial del derecho es la dignidad personal contenida en el art. 10.1 CE, resultando en

54 STS, Sala de lo Penal, Sección $1^{\text {a }}$, 4/2017, de 18 de enero.

55 Razonamientos recogidos, entre otras, en las SSTC 176/1995, de 11 de diciembre, 48/2003, de 12 de marzo, 174/2006, de 5 de junio, 177/2015, de 22 de julio y 112/2016, de 20 de junio.

56 Valga en el sentido de lo desarrollado hasta aquí, en referencia expresa al art. 510, contemplado entre «los delitos cometidos con ocasión del ejercicio de los derechos fundamentales y de las libertades públicas garantizados por la Constitución», de la Sección $1^{\text {a }}$, del Capítulo IV «Delitos relativos al ejercicio de los derechos fundamentales y libertades públicas», del Título XXI, «Delitos contra la Constitución», del Libro II, «De los delitos y sus penas», de la LO 10/1995, de 23 de noviembre, del CP. 
sí mismo una garantía constitucionalmente vinculada al derecho a la no discriminación recogido en el art. 14 CE. En base a ambos, el marco constitucional que garantiza la libertad de expresión recogida en el art. 20.1 CE quedaría singularmente restringido bajo los estrictos parámetros de la casuística, respecto de las expresiones intolerantes que definen los delitos de odio ${ }^{57}$.

\section{B. El juicio de ponderación frente a los límites de la libertad de expresión.}

Según lo anterior, los límites específicos a la libertad de expresión vendrían únicamente justificados una vez acreditada la necesidad de sancionar o prevenir aquellas formas de expresión que propaguen, promuevan o justifiquen el odio basado en la intolerancia, poniendo en peligro el derecho a la dignidad de la persona o los colectivos afectados, así como las garantías de igualdad y no discriminación contempladas en los arts. $10.1 \mathrm{CE}$ y $14 \mathrm{CE}^{58}$. Dicha restricción deberá ir siempre precedida de un análisis equilibrado y sensato de las expresiones presuntamente discriminatorias, respecto

57 Este es en esencia el argumento que desde bien temprano fue asumido por la jurisprudencia internacional en materia de Derechos Humanos a la hora de interpretar el mandato contenido en el art. $10 \mathrm{CEDH}$. Fundamentalmente desde la STEDH, Caso Handsyde contra Reino Unido, de 7 de diciembre de 1976, en la que se estableció que el derecho a la libertad de expresión se compadece con la posibilidad de establecer condiciones, restricciones o sanciones que salvaguarden la protección de otros derechos, siempre que las mismas sean congruentes y proporcionadas al objetivo legítimo perseguido, careciendo por el contrario de efecto legitimador cuando las mismas se ejercitasen de modo desmesurado y exorbitante. BOE, de 10 de octubre de 1979. Convenio para la protección de los Derechos Humanos y de las Libertades Fundamentales, firmado en Roma el 4 de noviembre de 1950. La Unión Europea incorporó el mandato de la adhesión al Convenio, en el art. 6.2 vigente Tratado de Lisboa, firmado por los Estados miembros el 13 de diciembre de 2007. Principio de proporcionalidad que fue acogido por vez primera por la STC $62 / 1982$, de 15 octubre, reiterado entre otras en las SSTC $185 / 2002$, de 14 de octubre y 235/2007, de 7 de noviembre. Así lo entiende también la jurisprudencia ordinaria, entre otras SSTS, Sala de lo Penal, Sección 1a , 259/2011, de 12 de abril, 314/2015, de 4 de mayo, 646/2018, de 14 de diciembre, 47/2019, de 4 de febrero, y 185/2019, de 2 de abril, para la que «la Constitución no prohíbe las ideologías que se sitúan en los extremos del espectro político. Incluso aún podría decirse que tampoco prohíbe las ideas que por su extremismo se sitúen fuera de ese amplio espectro político, por muy rechazables que puedan considerarse desde la perspectiva de los valores constitucionales. Lo que ocurre es que cuando se trata de conductas dotadas de una suficiente gravedad, el legislador puede limitar la intervención penal para aquellos hechos que supongan un resultado de lesión o la creación de un peligro, que aunque abstracto debe ser real, para la integridad de esos bienes jurídicos».

58 Y ello pese a la autorizada doctrina que ha venido entendiendo que dicho razonamiento supone un adelanto injustificado de la barrera punitiva del Estado, fundamentalmente MUÑOZ CONDE, Francisco, Derecho Penal: parte especial, Tirant lo Blanch, Valencia, 2004, págs. 823- 824. 
de las que, tal y como refieren las SSTC 177/2015, de 22 de julio, y $112 / 2016$, de 20 de junio $^{59}$, no es necesario inferir una situación de peligro concreto, aunque sí de una aptitud o ánimo agresivo, suficientemente serio como para colisionar con otros bienes jurídicos acreedores de mayor protección ${ }^{60}$, superando la tesis que abogaban por aplicar una primacía de derechos en favor de la dignidad de la persona y la igualdad de los seres humanos.

En efecto, la doctrina constitucional entiende que en estos casos debe prevalecer un juicio previo, riguroso y ponderado, de compensación valorativa ${ }^{61}$, pues tal y como se razonaba en la STC 31/2018, de 10 de abril: "A diferencia del principio genérico de igualdad, que no postula ni como fin ni como medio la paridad y sólo exige la razonabilidad de la diferencia normativa de trato, las prohibiciones de discriminación contenidas en el art. 14 CE implican un juicio de irrazonabilidad de la diferenciación establecida ex Constitutione, que imponen como fin y generalmente como medio la parificación, de manera que sólo pueden ser utilizadas excepcionalmente por el legislador como criterio de diferenciación jurídica, lo que implica la necesidad de usar en el juicio de legitimidad constitucional un canon mucho más estricto, así como un mayor rigor respecto a las exigencias materiales de proporcionalidad (SSTC 126/1997, de 3 de julio, con cita de las SSTC 229/1992, de 14 de diciembre, 75/1983, de 3 de agosto y 209/1988, de 10 de noviembre. También resulta que

59 Vid. SSTC 177/2015, de 22 de julio, y 112/2016, de 20 de junio, directamente aplicada en SSTS, Sala de lo Penal, Sección $1^{a}, 820 / 2016$, de 2 de noviembre, 335/2017, de 11 de mayo, 72/2018, de 9 de febrero, 79/2018, de 15 de febrero, 648/2018, de 14 de diciembre, 47/2019, de 4 de febrero, 59/2019, de 5 de febrero y 185/2019, de 2 de abril. No obstante, la doctrina constitucional emanada del Tribunal Europeo de Derechos Humanos en esta materia, había sido aplicada por primera vez en la SAP de Barcelona, Sección 2a, 713/2014, de 22 de julio.

60 Para la STS 259/2011, de 12 de abril, «la restricción del derecho, y más aún cuando se recurre a la sanción penal, requiere de una justificación que sólo se encuentra, en palabras del Tribunal Constitucional, cuando colisiona con otros bienes jurídicos defendibles que se revelen acreedores de una mayor protección tras la necesaria y previa labor de ponderación. Y no sólo eso, sino que será preciso que las características de la colisión sean tales que justifiquen la intervención penal».

61 Un juicio previo de valoración en el que, según la STS, Sala de lo Penal, Sección $1^{\mathrm{a}}, 752 / 2012$, de 3 de octubre, proceda «examinar si los hechos exceden los márgenes del ejercicio de los derechos fundamentales que en ellos se protegen, ya que, de no llegar a esta conclusión, la acción no podría prosperar, puesto que las libertades del art. 20.1 CE operarían como causas excluyentes de la antijuridicidad de esa conducta. Parece evidente que unos mismos hechos "no pueden ser (...) valorados como actos de ejercicio de un derecho fundamental y como conductas constitutivas de un delito. Se impone, por tanto, un ineludible ejercicio de compensación valorativa que viene amparado por la propia normativa reguladora de estos derechos». 
en tales supuestos la carga de demostrar el carácter justificado de la diferenciación recae sobre quien asume la defensa de la misma y se torna aún más rigurosa que en aquellos casos que quedan genéricamente dentro de la cláusula general de igualdad del art. $14 \mathrm{CE}$, al venir dado el factor diferencial por uno de los típicos que el art. 14 $\mathrm{CE}$ concreta para vetar que en ellos pueda basarse la diferenciación, como ocurre con el sexo, la raza, la religión, el nacimiento y las opiniones (STC 81/1982, de 21 de diciembre)» ${ }^{62}$.

Por su parte, en la STS, Sala de lo Penal, Sección 1a , 646/2018, de 14 de diciembre, se insistió en la obligatoriedad de establecer en estos casos ese juicio ponderado, que no debe excluir necesariamente otros parámetros para discernir cuando lo inaceptable se convierte en delictivo, puesto, que, en un razonamiento seguido posteriormente en las SSTS, Sala de lo Penal, Sección 1 ${ }^{\mathrm{a}}$, 2/2019, de 7 de enero, 47/2019, de 4 de febrero, y 185/2019, de 2 de abril, venía a concluir que, efectivamente, «entre el odio que incita la comisión de delitos, el odio que siembra la semilla del enfrentamiento y erosiona los valores esenciales de la convivencia, y el odio que se identifica con la animadversión o el resentimiento, existen matices que no pueden ser orillados por el juez penal con el argumento de que todo que lo que no es acogido en que la libertad de expresión resulta intolerable y, por ello, necesariamente delictivo», estableciendo a continuación una serie de pautas que coadyuvan a delimitar los delitos de odio:

«A) En primer lugar, el autor debe seleccionar a sus víctimas por motivos de intolerancia, y dentro de los colectivos vulnerables a los que alude la norma, exigencia que también juega respecto de las víctimas de delitos terroristas.

B) En segundo lugar, la conducta no sólo atemoriza a la persona destinataria del mensaje, sino a todo el colectivo al cual pertenece, creando sentimientos de lesión de la dignidad, de inseguridad y de amenaza.

C) Las expresiones realizadas deben agredir, también, a las normas básicas de convivencia basadas en el respeto y la tolerancia, de manera que toda la sociedad se vea concernida por la expresión de las ideas que contrarían abiertamente los mensajes de tolerancia que el ordenamiento jurídico, como instrumento de control social, expone a la ciudadanía que los hace propios, lo que permitiría excluir de la consideración aquellas

62 STC 31/2018, de 10 de abril, 
opiniones sobre personas de notoriedad pública por su actuación y sometidas a cuestionamiento ciudadano.

D) Además, debe tratarse de mensajes que merezcan una calificación de graves y serios para la incitación a la comisión de actos terroristas (art. $579 \mathrm{CP}$ ), o la generación del sentimiento de odio, aptitud y seriedad para conformar un sentimiento lesivo a la dignidad.

E) El ánimo que persigue el autor es el de agredir, lo que permitiría excluir las manifestaciones pretendidamente hilarantes y las que se efectúan desde la venganza puntual, desprovistas de la necesaria mesura» ${ }^{63}$.

\section{LAS ALTERNATIVAS PENALES: DE LA ESPECIALIZACIÓN EN LA PERSECUCIÓN DELITIVA A LOS SISTEMAS DE FILTRADO Y LA AUTORREGULACIÓN DE LAS CONDUCTAS.}

Tras la reforma penal operada con la LO 1/2015, de 30 de marzo, la identificación y persecución de los delitos de odio se vio favorecida por la entrada en vigor de la Ley Orgánica 13/2015, de 5 de octubre, de modificación de la Ley de Enjuiciamiento Criminal (LECr.) para el fortalecimiento de las garantías procesales y la regulación de las medidas de investigación tecnológica, al mismo tiempo que la Ley 41/2015, de 5 de octubre, de modificación de la LECr. para la agilización de la justicia penal y el fortalecimiento de las garantías procesales, que facultaron el impulso para la aplicación de los protocolos policiales en redes sociales, en cuanto a mensajes ofensivos y degradantes, aprobados apenas unos meses antes ${ }^{64}$. Dichos protocolos contenían indicadores y ordenaban pautas para validar evidencias y testimonios que coadyuvaran a la formación del correspondiente atestado, así como facilitar procedimientos para poner en conocimiento del Fiscal Delegado Provincial para la Tutela Penal de la Igualdad y contra la Discriminación, todo tipo de hechos relacionados con las mencionadas actividades delictivas.

63 SSTS, Sala de lo Penal, Sección 1ª 648/2018, de 14 de diciembre, 47/2019, de 4 de febrero.

64 Ambas leyes fueron publicadas en el BOE de 6 de octubre de 2015, mientras que en el mes de diciembre anterior resultó aprobado el Protocolo de actuación de las Fuerzas y Cuerpos de Seguridad para los delitos de odio y conductas que vulneran las normas legales sobre discriminación, accesible en http://www.interior.gob. es/documents/642012/3479677/PROTOCOLO+ACTUACION/99ef64e5-e062-46348e58-503a3039761b [Consultado el 9 de octubre de 2019]. 
Tanto la Brigada de Investigación Tecnológica de la Policía Nacional como el Grupo de Delitos Telemáticos de la Guardia Civil se encuentran al servicio de la autoridad judicial en los términos previstos en el art. $282 \mathrm{LECr}$, por lo que la especialización de las fiscalías territoriales que tiene lugar a partir del año 2013, ha logrado promover en esta materia un canal directo con el ciudadano. Las tesis que abogaban por una especialización de los operadores jurídicos encargados de la persecución de este tipo de delitos, defienden que las medidas implementadas han conseguido cualificar el número de denuncias, supliendo de algún modo las declaraciones hasta entonces faltas de elementos acreditativos de la motivación discriminatoria. Y lo cierto es que, una vez interpuestas las mismas y descartada intervención previa a la comisión del delito que garantiza el art. 20.2 $\mathrm{CE}^{65}$, dado que una rápida retirada o bloqueo del acceso a los contenidos ilícitos resulta esencial para limitar su difusión y los consiguientes perjuicios, existen una serie de medidas en estos casos que facultan al juez para ordenar la retirada, inutilización, borrado o destrucción de soportes y archivos digitales en los que se contienen las expresiones odiosas y discriminatorias, junto al bloqueo del acceso a portales y páginas web que sirven de cauce para la difusión de dichas manifestaciones ${ }^{66}$, así como a la interrupción en la prestación de contenidos telemáticos ${ }^{67}$.

En el primer caso, las medidas se ajustan a las previsiones del art. 13 LECr, asimilándose a las contempladas expresamente en rela-

65 Para Domingo Monforte una de las diligencias más invasivas que se pueden adoptar dentro en fase de investigación en este tipo de procesos, es la intervención judicial de las comunicaciones telefónicas, correos electrónicos o whatsapp que pueden afectar de lleno al derecho fundamental al secreto de las comunicaciones que protege y garantiza el derecho a la intimidad. DOMINGO MONFORTE, José, «La intervención judicial de las comunicaciones», Actualidad Jurídica Aranzadi, núm. 896, 2014, pág. 12.

${ }_{66}$ Resulta interesante señalar que en estos casos no es necesaria la incautación policial del ordenador y bastaría una intervención virtual del mismo a través de la computación en nube o "cloud computing», tal y como apunta ANGULO GARZARO, Amaya. "Límites a la utilización de las redes sociales como medio de expresión: la lesión al honor o la imagen y el despido como consecuencias indeseables», Revista Aranzadi de Derecho y Nuevas Tecnologías, num.43, 2017, pág. 13.

67 Art. 510.6 CP «El juez o tribunal acordará la destrucción, borrado o inutilización de los libros, archivos, documentos, artículos y cualquier clase de soporte objeto del delito a que se refieren los apartados anteriores o por medio de los cuales se hubiera cometido. Cuando el delito se hubiera cometido a través de tecnologías de la información y la comunicación, se acordará la retirada de los contenidos. En los casos en los que, a través de un portal de acceso a internet o servicio de la sociedad de la información, se difundan exclusiva o preponderantemente los contenidos a que se refiere el apartado anterior, se ordenará el bloqueo del acceso o la interrupción de la prestación del mismo». 
ción con los delitos de pornografía infantil del art. $189.8 \mathrm{CP}$, propiedad intelectual del art. 270.3 CP y terrorismo del art. 578.4 CP, introducidas en la misma reforma de la LO 1/2015, de 30 de marzo, por lo que en principio su aplicación no resultaría problemática más allá de la legitimación para instarla y de los sujetos obligados a su cumplimiento ${ }^{68}$. Los prestadores nacionales de servicios de alojamiento de datos deberían coadyuvar a ello cuando la autoridad judicial solicite la determinación de la autoría, aunque la dificultad para perseguir los delitos de odio realizados a través de redes sociales estriba, fundamentalmente, en los casos en los que el requerimiento de bloqueo o interrupción de servicios deba instarse ante mercantiles localizadas en terceros países, con diferente valoración y tratamiento legislativo de las conductas delictivas.

Por otro lado, el problema del anonimato en redes sociales, la encriptación de datos y la falta de identificación fidedigna es un reproche recurrente en todas las memorias fiscales aprobadas tras entrada en vigor de la reforma de la LECr de 2015, aparentemente encuentra difícil solución ${ }^{69}$, aunque también es cierto que algunas multinacionales del sector han comenzado a implementar sistemas de acceso autentificado a sus contenidos, tratando de fomentar el uso responsable las mismas y el respeto a las opiniones del resto de usuarios $^{70}$. En todo caso, la tendencia en la Era de la globalización de las comunicaciones parece ser más bien la contraria, como con tanto acierto profetizaba el profesor Muñoz Machado hace jus-

68 En el primer caso y si bien el art. 588 bis b LECr determina a la Policía Judicial y al Ministerio Fiscal como sujetos legitimados para instar las medidas cautelares, la Circular de la Fiscalía General del Estado 1/2019, de 6 de marzo, entiende que también estaría legitimado de oficio el juez de instrucción como responsable último de la investigación. Por lo que respecta a los sujetos obligados a llevar a cabo y colaborar en la medida, la misma Circular interpreta que se refiere a las personas o entidades que gestionen servicios privados de telecomunicación o de almacenamiento de datos, mercantiles que comercialicen programas informáticos que gestionen almacenamiento de datos en equipos informáticos o incluso cualquier persona física o compañía a la que se requiera por el juzgado para posibilitar la efectividad de una medida de investigación. Circular de la Fiscalía General del Estado 1/2019, de 6 de marzo, Disposiciones comunes y medidas de aseguramiento de las diligencias de investigación tecnológicas en la Ley de Enjuiciamiento Criminal. BOE, de 22 de marzo de 2019.

69 El vigente art. 284 LECr. establece que, salvo determinados supuestos, la Policía Judicial no remitirá los atestados a la Fiscalía cuando el autor del delito no se encuentre identificado.

${ }_{70}$ Un ejemplo de ello es Facebook que permite informar a los responsables de la red social sobre aquellos perfiles que no coincidan con la realidad. BASTERRECHEA, Natalia, "Facebook: enfoque innovador al servicio de la protección», en PÉREZ ÁLVAREZ, Salvador (Coord.), Menores e Internet, Thomson Reuters Aranzadi, Pamplona, 2013, pág. 449. 
tamente tres décadas, advirtiendo sobre la inanidad de establecer controles efectivos frente a su naturaleza autárquica ${ }^{71}$. En efecto, el carácter abierto y universal de las redes sociales dificulta la armonización de un marco legal internacional e impide la aplicación en muchos casos del Derecho interno, de tal forma que pueden llegar a generar indeseados efectos para el legislador nacional cuando, tal y como apunta Sieber, los ciudadanos comprometan su autoridad tras percibir la fuga de los presuntos autores hacia medios o cauces menos restrictivos o controlables ${ }^{72}$.

Esta es una de las razones que esgrimen quienes, ante la imposibilidad de acordar y coordinar medidas efectivas en el marco del ordenamiento jurídico internacional, aconsejan implementar mecanismos de autorregulación, así como códigos de conducta preventivos, que limiten los daños generados por el ciberodio a través de redes sociales $^{73}$. Algunos estudios centrados en la actividad del Grupo de Delitos Telemáticos de la Guardia Civil, subrayan precisamente que el compromiso de los usuarios para desenvolverse en un espacio virtual dominado por prácticas éticas es cada vez mayor, prestándose voluntarios a rastrear y denunciar cada vez más a menudo las expresiones odiosas o denigrantes del resto de participantes ${ }^{74}$.

La potenciación del papel de los moderadores a través de códigos deontológicos de conducta en redes sociales resulta una propuesta interesante para la resolución del problema que requiere, no obstante, un correlato práctico respecto a las empresas prestadoras de estos servicios que tiene que ver con la autorregulación, los sistemas de filtrado ${ }^{75}$ y la verificación o fiabilidad de las informaciones viralizadas a través de las mismas, conocidas comúnmente como "fakenews». A través de los proveedores de servicios es posible monitorizar, controlar o restringir cualquier acceso a

71 MUÑOZ MACHADO, Santiago, «La reserva de jurisdicción», La Ley, 1989, págs. 155 y ss.

72 SIEBER, Ulrich: «La lucha contra el odio en Internet. Fundamentos técnicos, jurídicos y estratégicos para un concepto de prevención», Revista de Ciencias Penales, núm. 4, 2001-2002, p. 169

73 Entre otros argumentos y como razona algún autor, porque criminalizar los discursos de grupos extremistas podría conllevar la eventual victimización de los mismos, otorgándoles un inmerecido protagonismo. TERUEL LOZANO, G. M., «Expresiones...», Ob. cit., pág. 195.

74 ORTEGA MALDONADO, Álvaro, "Las redes sociales como herramienta de control ético de Internet», en SUÁREZ-VILLEGAS, Juan Carlos (Coord.) La ética de la comunicación a comienzos del siglo XXI. Edufora, Sevilla, 2011, págs. 1236-1237.

75 Una introducción a los distintos sistema de bloqueo y filtrado en FERNÁNDEZ ESTEBAN, $\mathrm{M}^{\mathrm{a}}$. Luisa, "Internet y los derechos fundamentales», Anuario jurídico de La Rioja, núm. 6-7, 2001, pág. 342. 
Internet, así como también bloquear el uso de determinadas páginas web. Sin embargo, no existe una armonización legislativa a nivel internacional que obligue a los Estados con sistemas más limitadores de la libertad de expresión a fomentar códigos éticos entre los usuarios, ni a los menos restrictivos de la libertad de empresa a implementar medidas de autorregulación en las mismas. El propio Código de Conducta para la lucha contra la Incitación Ilegal al Odio en Internet promovido por la Comisión Europea, subrayó la irresolución de este problema admitiendo que «a la hora de adoptar medidas en relación con los contenidos ilícitos en línea, los Estados miembros deben respetar el principio del país de origen establecido en la Directiva 2000/31/CE. Por consiguiente, no pueden, por razones inherentes al ámbito coordinado, tal como se especifica en la misma, restringir la libre prestación de servicios de la sociedad de la información por prestadores establecidos en otro Estado miembro ${ }^{76}$.

A nuestro entender, dicha circunstancia resulta crucial a la hora de abordar el problema por lo que deberá ser obligatoriamente prevista entre los elementos a ponderar respecto a la proporcionalidad de los fines, los medios técnicos disponibles, así como los eventuales efectos que puedan tener sobre el ejercicio de la libertad de expresión cualquier tipo de propuesta de medidas conjuntas a las ya articuladas por el ordenamiento jurídico, encaminadas a la persecución y erradicación del delito de ciberodio en redes sociales.

\section{CONCLUSIONES.}

Los datos oficiales muestran en sus distintas series históricas un aumento exponencial en la comisión de delitos relacionados con las TICs. La ciberdelincuencia, como comúnmente es conocida, se ha convertido en un problema de índole internacional frente al que las legislaciones nacionales tan solo pueden oponer soluciones paliativas. En muchos casos, la alarma social generada ante el incremento de la misma, promueve medidas urgentes por parte de los poderes públicos que usualmente van acompañadas de innovaciones del ordenamiento jurídico carentes de la reflexión y el consenso necesario para el abordaje correcto del problema. Sin tener en consideración el principio de intervención mínima ni el carácter de «ultima ratio» que representa

76 Recomendación 2018/334/UE de la Comisión, de 1 de marzo de 2018, sobre medidas para combatir eficazmente los contenidos ilícitos en línea. DOUE, de 6 de marzo de 2018. 
el Derecho Penal, reservado para aquellas manifestaciones discriminatorias más graves y atentatorias de las garantías constitucionales, el legislador lo ha convertido en el marco preferido para apuntalar los efectos de este tipo de decisiones tomadas de manera apresurada.

Un ejemplo paradigmático de esto último es la configuración jurídica del ciberodio. Los delitos de odio ejecutados y transmitidos en nuestro país a través de las TICs alcanzaron sustancialidad propia en el art. $510.3 \mathrm{CP}$, tras la reforma penal operada mediante LO $1 / 2015$, de 30 de marzo, y desde entonces las redes sociales se han transformado en el principal instrumento de difusión para toda clase de expresiones humillantes y discriminatorias contra grupos y colectivos minoritarios. Sin embargo, en la mayoría de las ocasiones la persecución penal del ciberodio encuentra obstáculos insalvables en el principio de acción extraterritorial, en la localización de servidores y prestadores de servicios en terceros países, así como en la encriptación de datos y el anonimato del que se sirven los presuntos autores para eludir la acción de la justicia, entre otros muchos factores que favorecen el incremento, año tras año, de esta modalidad delictiva. La Unión Europea ha tratado de reducir algunos de estos obstáculos, adoptando convenios en los que las grandes multinacionales del sector se comprometen a fomentar el uso racional de las redes sociales y a bloquear los contenidos indeseados, pero ello no basta.

En nuestro país, el principal desafío al que se enfrentan los tribunales a la hora de determinar el injusto del tipo que caracteriza los delitos de ciberodio ejecutados en redes sociales, tiene que ver con la deficiente delimitación jurídica de sus caracteres, que afecta de manera directa al derecho de libertad de expresión reconocido en el art. $20.1 \mathrm{CE}$, que eventualmente puede llegar a amparar manifestaciones groseras u ofensivas del lenguaje asimilándolas a meras expresiones intolerantes. Expresiones en su caso reprochables desde el punto de vista ético o social, pero dudosamente encuadrables dentro del tipo penal, pues tal y como está configurado en el art. $510 \mathrm{CP}$ este se encuentra reservado para aquellas otras manifestaciones discriminatorias o excluyentes más graves, atentatorias del derecho a la dignidad personal o colectiva, y fundadas siempre en motivos racistas, antisemitas u otros referentes a la ideología, religión o creencias, situación familiar, la pertenencia de sus miembros a una etnia, raza o nación, su origen nacional, su sexo, orientación o identidad sexual, por razones de género, enfermedad o discapacidad.

La dificultad de establecer con precisión esa línea delimitadora entre el derecho fundamental de libertad de expresión que repre- 
senta el elemento singularizador propio de las redes sociales, y aquellas otras manifestaciones basadas en la intolerancia, que lo trasgreden, promoviendo y justificando el odio frente a los derechos a la dignidad y no discriminación garantizados en los arts. 10 y $14 \mathrm{CE}$, ha llevado a la jurisprudencia a aplicar el principio de proporcionalidad en estos casos, infiriendo necesariamente de la casuística las presuntas conductas delictuales, a través de un juicio previo, riguroso y ponderado.

Con todo, la necesidad de acotar jurídicamente la construcción social que representa el concepto de odio, una noción esencialmente valorativa y cambiante, ha puesto el acento en las tesis que abogan por reforzar la acción penal a través de la especialización de los operadores jurídicos encargados de la persecución delictual, introduciendo asimismo medidas preventivas que incidan en la autorregulación de los prestadores de servicios, en sistemas de filtrado o en el fomento de códigos deontológicos entre los usuarios. No obstante, todo esfuerzo en este sentido deberá conjugarse con un marco jurídico internacional homogéneo y válido, así como con el compromiso de las grandes multinacionales del sector, si la pretensión última es la de articular medidas efectivas que venga a paliar el incremento de los delitos de ciberodio en redes sociales, sin duda alguna uno de los principales retos a los que se enfrenta el Derecho en nuestros días.

\section{BIBLIOGRAFÍA.}

Alcácer Guirao, Rafael, «Discurso del odio y discurso político. En defensa de la libertad de los intolerantes», Revista Electrónica de Ciencia Penal y Criminología, núm. 14, 2011.

AlCÁCER Guirao, RAFAel, «Libertad de expresión, negación del holocausto y defensa de la democracia. Incongruencias valorativas en la jurisprudencia del TEDH», Revista española de Derecho Constitucional, núm. 97, 2013.

Angulo Garzaro, Amaya. «Límites a la utilización de las redes sociales como medio de expresión: la lesión al honor o la imagen y el despido como consecuencias indeseables", Revista Aranzadi de Derecho y Nuevas Tecnologías, num.43, 2017.

Assiego Cruz, Violeta y otros, Delitos de Odio. Guía Práctica de la Abogacía, Fundación Abogacía Española, Madrid, 2018. 
BAsterrechea, NAtAlia, "Facebook: enfoque innovador al servicio de la protección», en PÉREZ ÁLVAREZ, Salvador (Coord.), Menores e Internet, Thomson Reuters Aranzadi, Pamplona, 2013.

CERECEDA FERnÁndeZ-Orduña, JaIME y otros, Informe sobre la evolución de los delitos de odio en España, Ministerio del Interior, Madrid, 2018.

DOMINGo Monforte, José, «La intervención judicial de las comunicaciones», Actualidad Jurídica Aranzadi, núm. 896, 2014.

Elósegui Itxaso, María, «Las Recomendaciones de la ECRI sobre Discurso del Odio y la adecuación del ordenamiento jurídico español a las mismas", Revista General de Derecho Canónico y Eclesiástico del Estado, núm. 44, 2017.

FERNÁNDEZ EsTEBAN, $M^{\mathrm{a}}$. LUISA, «Internet y los derechos fundamentales», Anuario jurídico de La Rioja, núm. 6-7, 2001.

Gómez MARTín, Victor, «Incitación al odio y género. Algunas reflexiones sobre el nuevo art. $510 \mathrm{CP}$ ", Revista electrónica de ciencia penal y criminología, núm. 18, 2016.

GOYEnA Huerta, Jaime, «Algunas cuestiones penales sobre el discurso del odio", Revista Aranzadi de Derecho y Proceso Penal, núm.49, 2018.

GUERRI FERnÁNDEZ, CRISTINA, «La especialización de la fiscalía en materia de delitos de odio y discriminación», InDret, Revista para el Análisis del Derecho, núm. 1, 2015.

LóPEz SÁNCHEZ, JAVIER, «Insultos online, ¿soluciones offline?», Actualidad Jurídica Aranzadi, núm. 91, 2015.

López Ortega, AnNA I., "Análisis y evolución de los delitos de odio en España (2011-2015)», Almenara. Revista Extremeña de Ciencias Sociales, núm. 9, 2015, págs. 80-81.

Moretón Toquero, $\mathrm{M}^{\mathrm{a}}$ ArÁnzazu, «El Ciberodio, la nueva cara del mensaje del odio: entre la cibercrimanlidad y la libertad de expresión». Revista Jurídica de Castilla y León, núm. 27, 2012.

Muñoz Conde, Francisco, Derecho Penal: parte especial, Tirant lo Blanch, Valencia, 2004.

Muñoz Machado, SANTIAgo, «La reserva de jurisdicción», La Ley, 1989.

Ortega Maldonado, Álvaro, «Las redes sociales como herramienta de control ético de Internet», en SUÁREZ-VILLEGAS, Juan Carlos 
(Coord.) La ética de la comunicación a comienzos del siglo XXI. Edufora, Sevilla, 2011.

Reuter, Nona (Coord.), Preventing and responding to hate crimes, OSCE, Varsovia, 2009.

Segarra Crespo, María José, Memoria elevada al Gobierno de S.M. presentada al inicio del año judicial por la Fiscal General del Estado, Imprenta Nacional de la Agencia Estatal del Boletín Oficial del Estado, Madrid, 2019.

SIEBER, UlRICH: «La lucha contra el odio en Internet. Fundamentos técnicos, jurídicos y estratégicos para un concepto de prevención», Revista de Ciencias Penales, núm. 4, 2001-2002.

TAJADURA TEJADA, JAVIER, «Libertad de expresión y negación del genocidio: comentario crítico a la STC de 7 de noviembre de 2007», Revista Vasca de Administración Pública, núm. 80, 2008.

Teruel Lozano, Germán M., «Libertad de expresión en Internet, control de contenidos de las páginas web y sus garantías constitucionales», Revista Aranzadi de Derecho y Nuevas Tecnologías, núm. 25, 2011.

Teruel Lozano, Germán M., «La libertad de expresión frente a los delitos de negacionismo y de provocación al odio y a la violencia: sombras sin luces en la reforma del Código penal», InDret: Revista para el Análisis del Derecho, núm. 4, 2015.

Teruel Lozano, Germán M. «Expresiones intolerantes, delitos de odio y libertad de expresión: un difícil equilibrio», Revista Jurídica de la Universidad Autónoma de Madrid, núm. 36, 2017. 